SUPPORTING INFORMATION

\title{
Warburg Effect Targeting Co(III) Cytotoxin Chaperone Complexes
}

\author{
Alexandra Glenister,§ Catherine K. J. Chen, ${ }^{\S}$ David J. Paterson, ${ }^{\#}$ Anna K \\ Renfrew, ${ }^{\S}$ Michela I. Simone, ${ }^{\dagger, *}$ and Trevor W. Hambley ${ }^{\S} *$ \\ $\S$ School of Chemistry, University of Sydney, New South Wales, 2006, Australia \\ \# Australian Synchrotron, ANSTO, 800 Blackburn Road, Clayton 3168, Victoria, Australia. \\ $\dagger$ Discipline of Chemistry, University of Newcastle, Callaghan, New South Wales, 2308, Australia.
}

\section{Corresponding Authors}

*Emails: trevor.hambley@sydney.edu.au (TWH) and michela.simone@newcastle.edu.au (MIS)

\section{ORCID}

Trevor W. Hambley: 0000-0003-1194-1896

Michela I Simone: 0000-0002-1339-8236 
HIGH RESOLUTION MASS SPECTRA
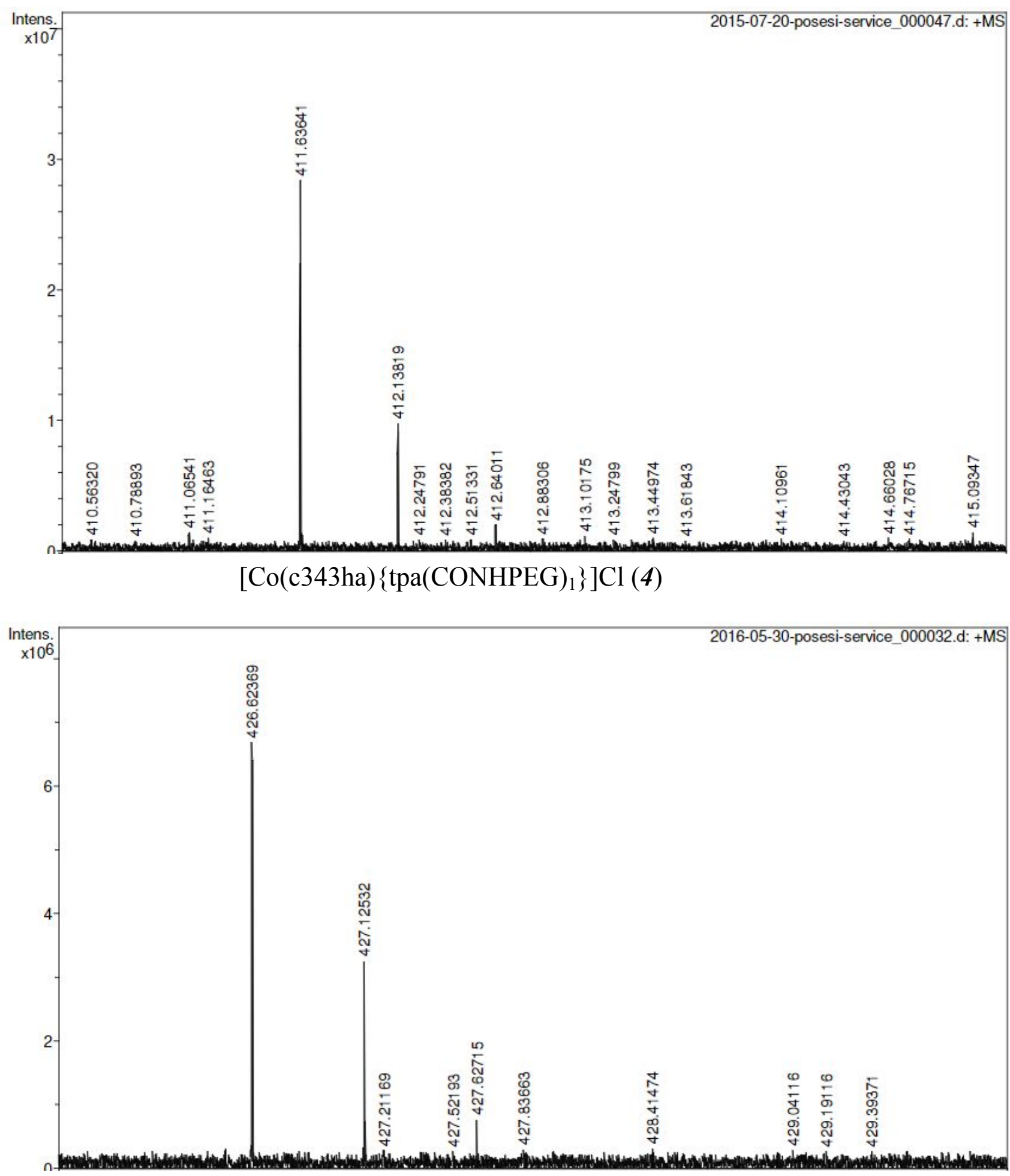

$\left[\mathrm{Co}(\mathrm{c} 343 \mathrm{haH})\left\{\operatorname{tpa}(\mathrm{CONHglucosamine})_{1}\right\}\right] \mathrm{Cl}_{2}(5)$ 


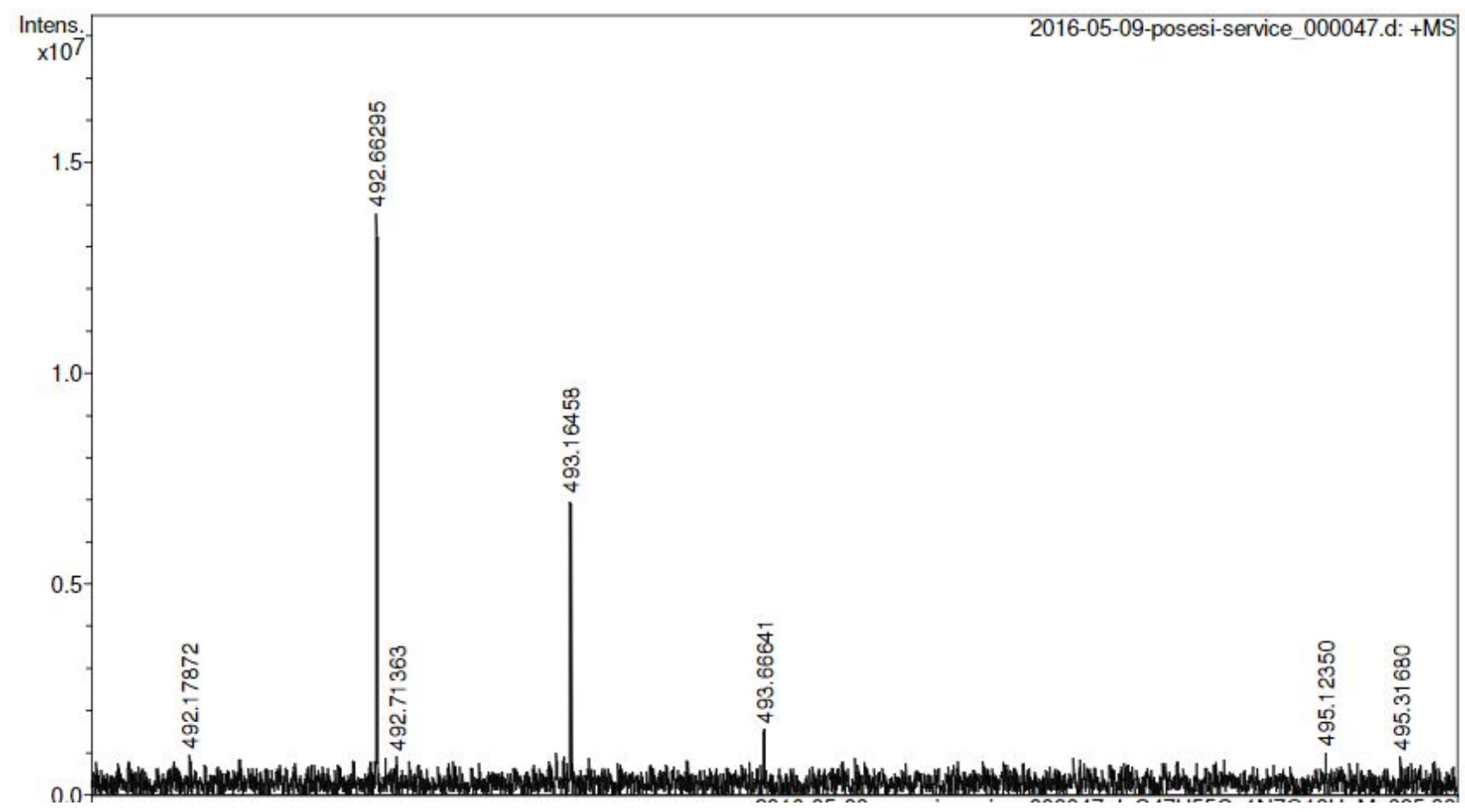

$\left[\mathrm{Co}(\mathrm{c} 343 \mathrm{haH})\left\{\operatorname{tpa}(\mathrm{CONHPEGglucose})_{1}\right\}\right] \mathrm{Cl}_{2}(\boldsymbol{\sigma})$ 

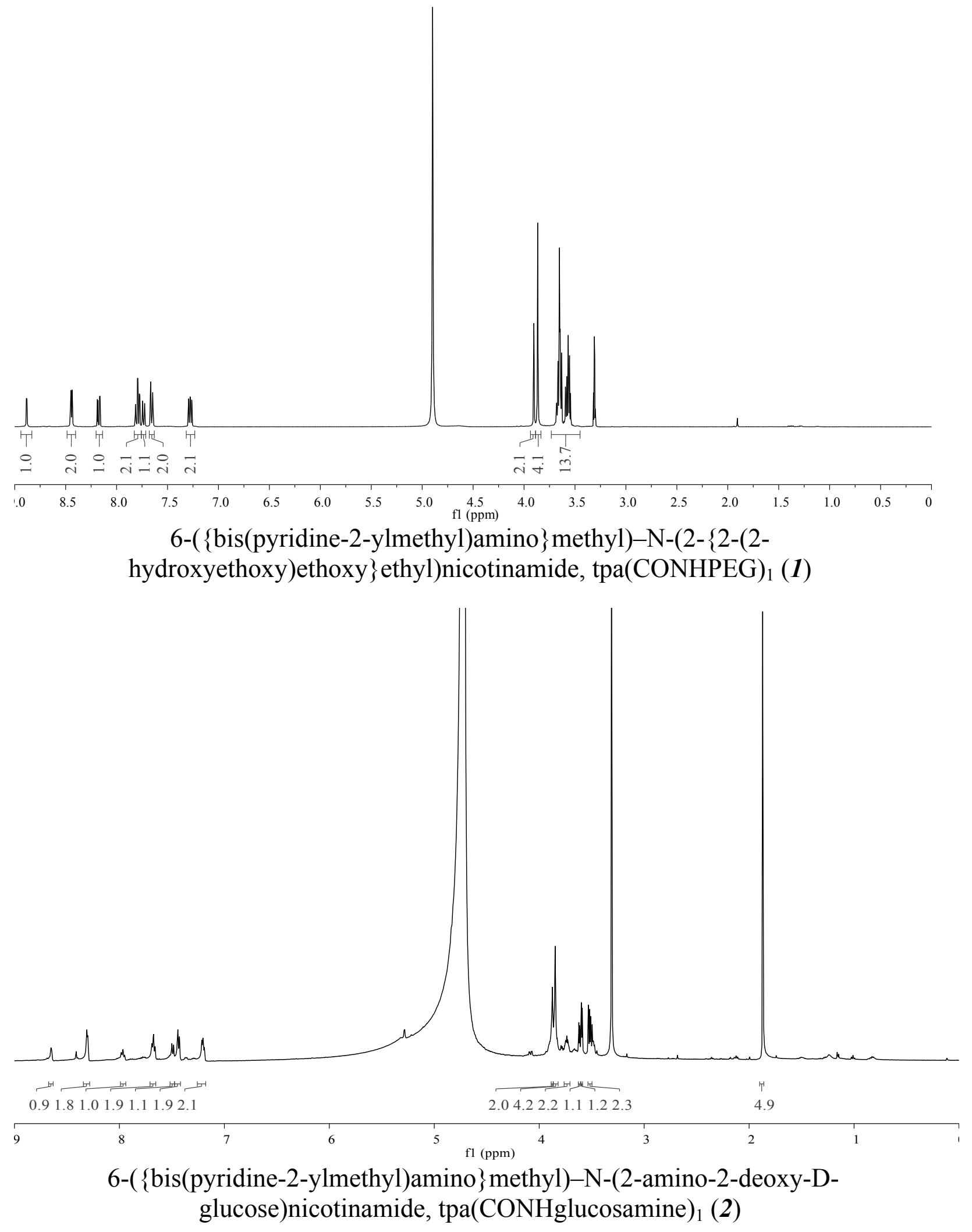


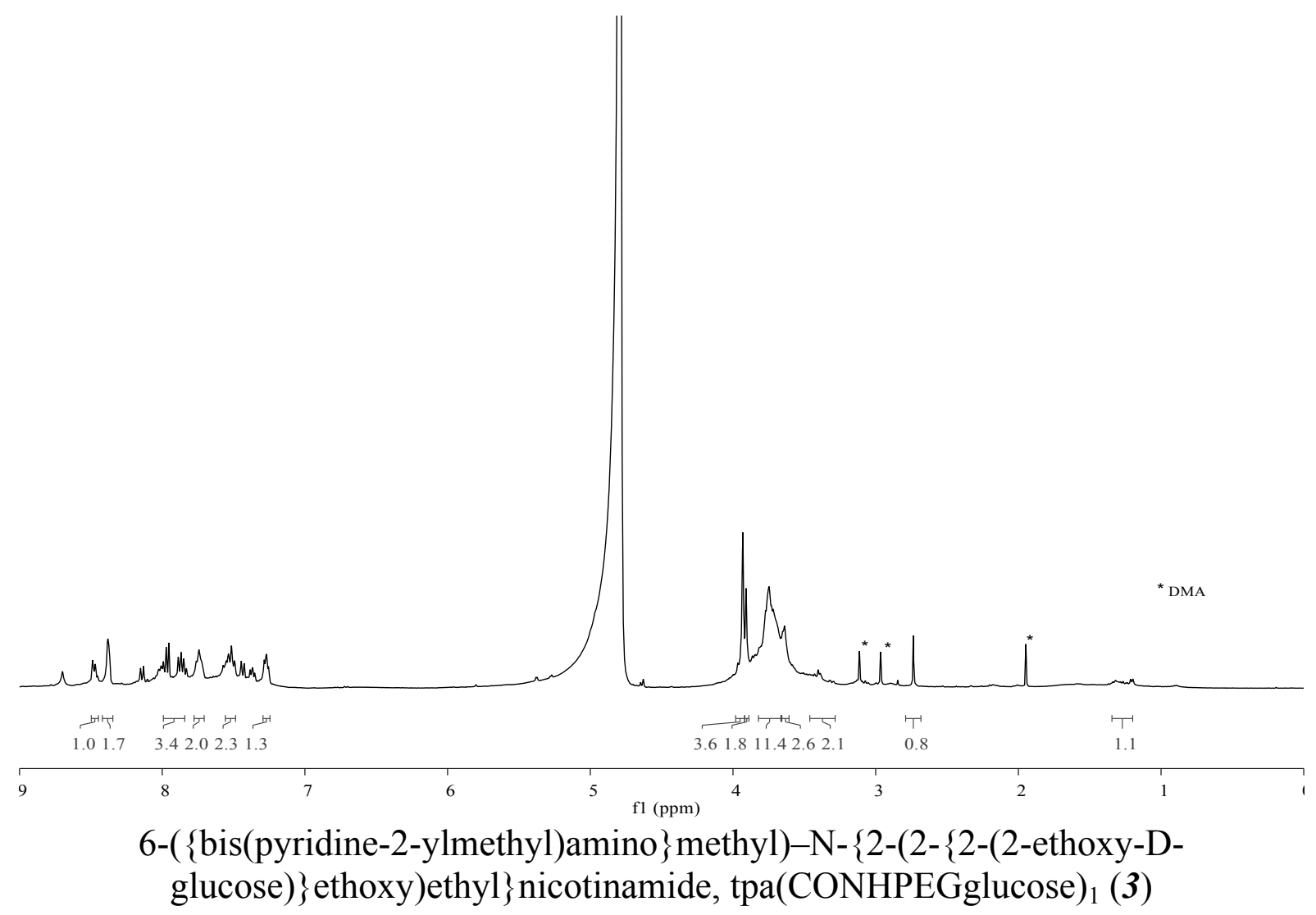




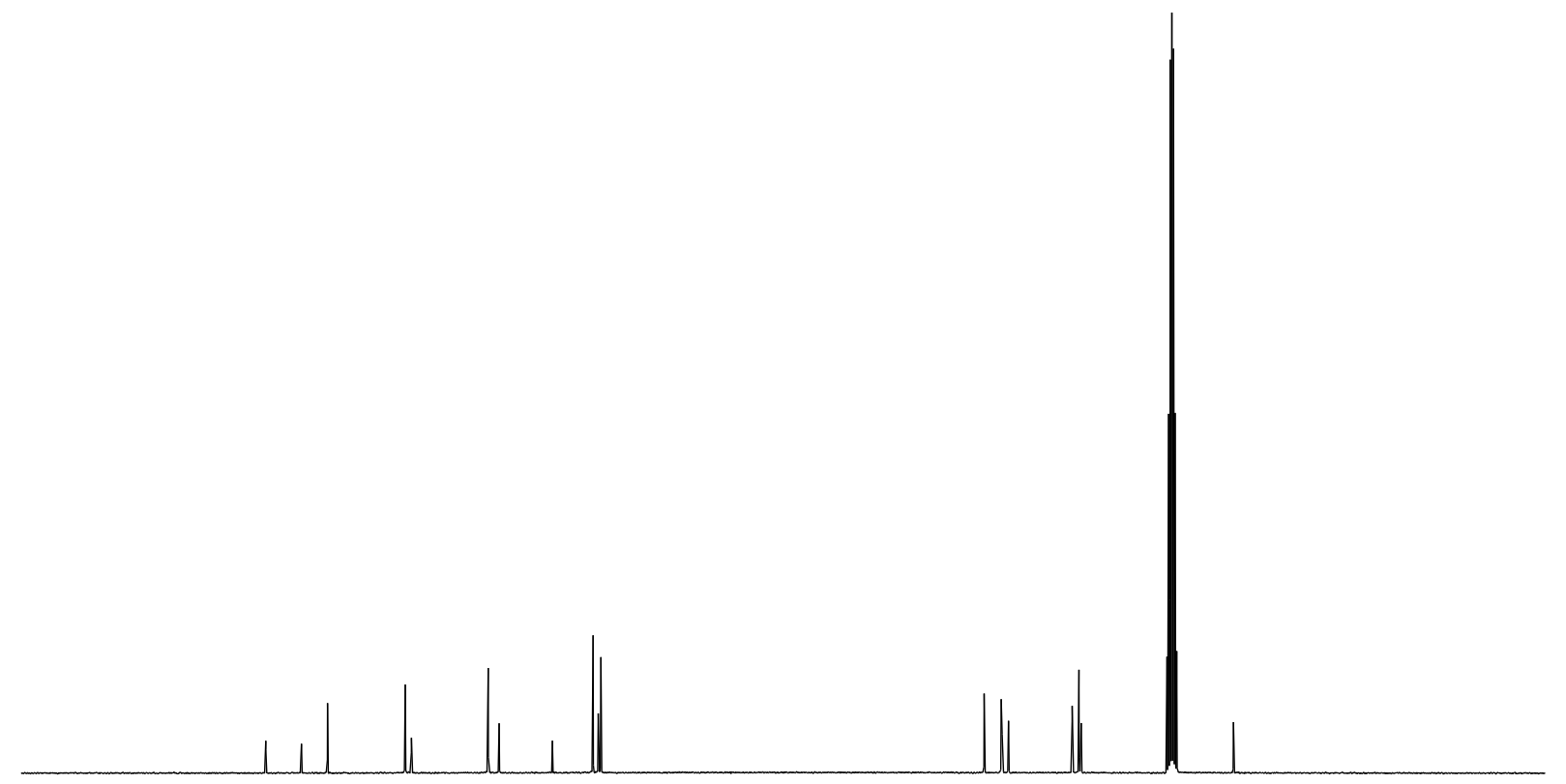

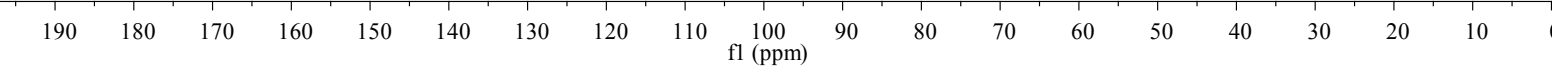

6-(\{bis(pyridine-2-ylmethyl)amino $\}$ methyl)-N-(2-\{2-(2-

hydroxyethoxy)ethoxy ethyl)nicotinamide, tpa(CONHPEG) $)_{1}(1)$

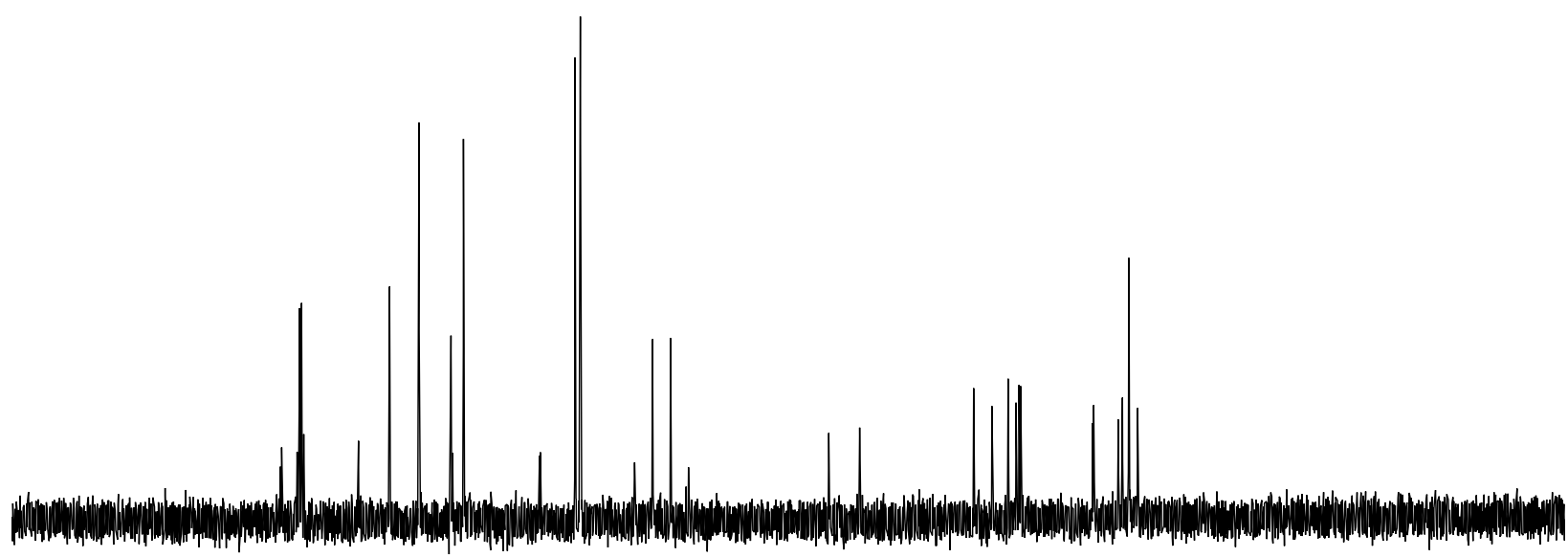

00 140 120 100
$\mathrm{f} 1(\mathrm{ppm})$ 80 40 20

6-(\{bis(pyridine-2-ylmethyl)amino $\}$ methyl)-N-(2-amino-2-deoxy-Dglucose)nicotinamide, tpa(CONHglucosamine $)_{1}(2)$ 


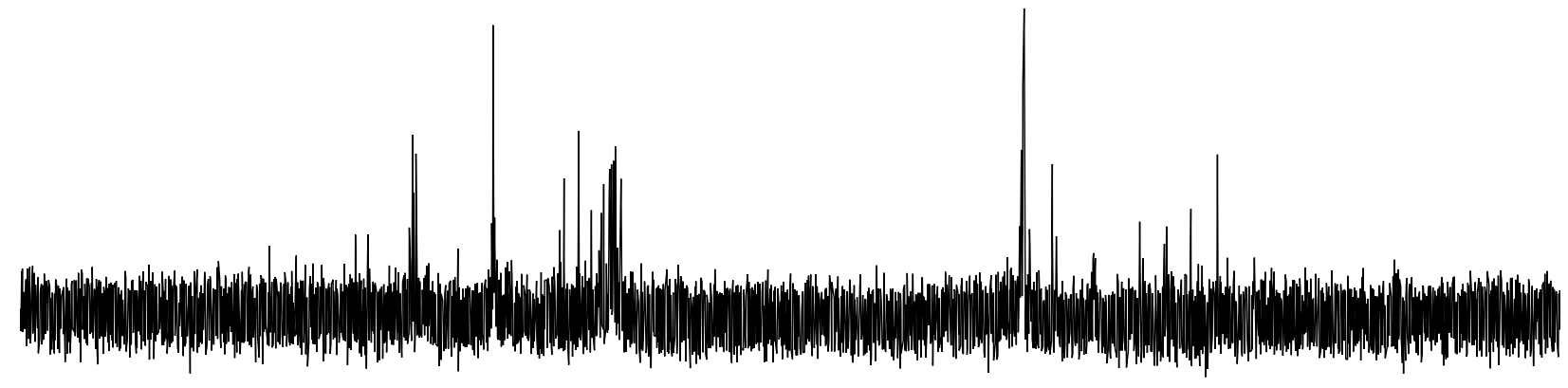

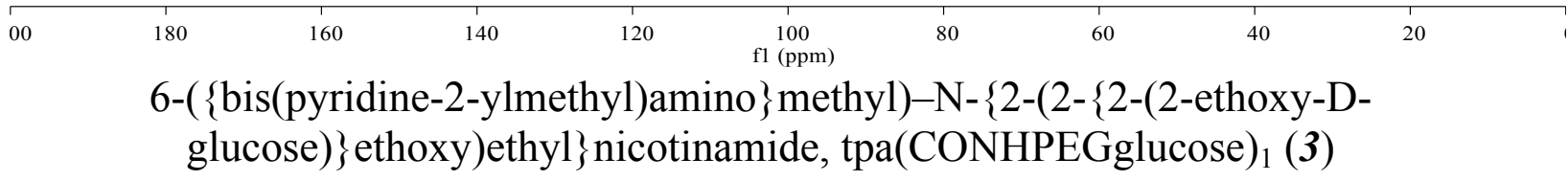


HEXOKINASE INHIBITION ASSAY

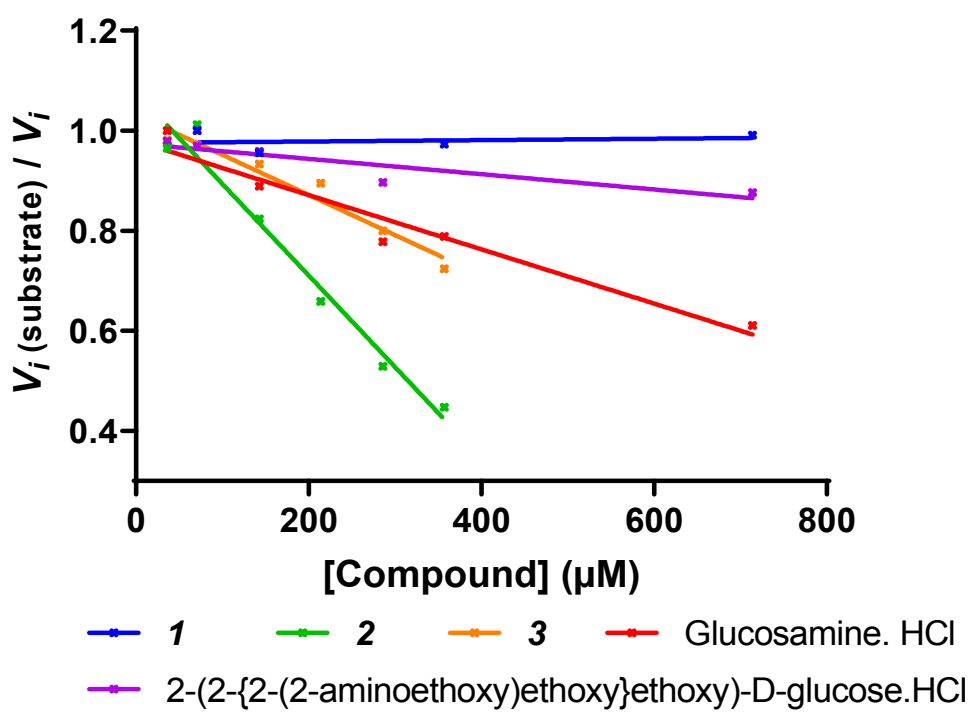

Figure S1. Plot of the relative rate of HK catalysed glucose phosphorylation in the presence of increasing concentration of compounds 
FLUORESCENCE IMAGING OF SPHEROIDS

A

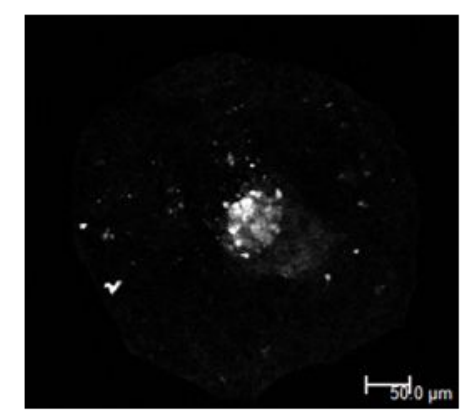

C

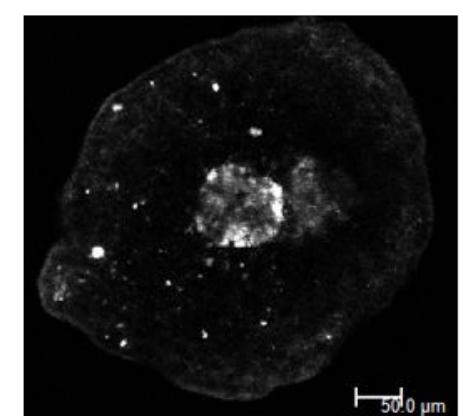

B

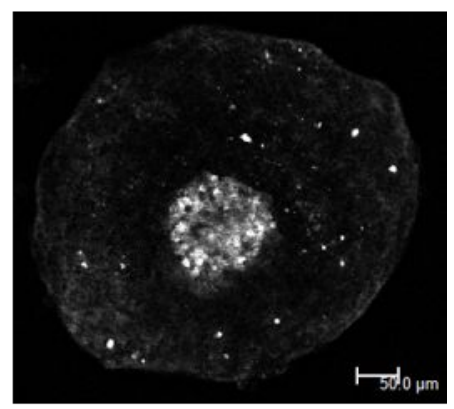

D

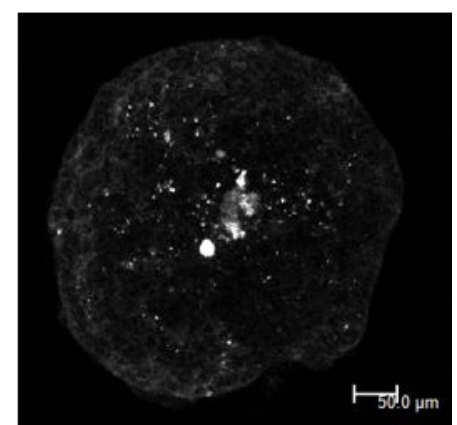

Figure S2. Multiphoton fluorescence microscopy images of DLD-1 spheroids, in low glucose DMEM, after dosing for 24 hours with $50 \mu \mathrm{M}$ : A c $343 \mathrm{haH}_{2} ; \mathbf{B}$ $\left[\mathrm{Co}(\mathrm{c} 343 \mathrm{ha})\left\{\mathrm{tpa}(\mathrm{CONHPEG})_{1}\right\}\right] \mathrm{Cl}(4) ; \mathbf{C}\left[\mathrm{Co}(\mathrm{c} 343 \mathrm{ha})\left\{\operatorname{tpa}(\mathrm{CONHglucosamine})_{1}\right\}\right] \mathrm{Cl}$ (5); D [Co(c343ha) $\left.\left.\{\text { tpa(CONHPEGglucose })_{1}\right\}\right] \mathrm{Cl}$ (6) 